\title{
Challenges and opportunities for green economy transformation of Gabrovo District
}

\author{
Nikolay Tsonkov ${ }^{1 *}$ \\ ${ }^{1}$ Scientific and Research center of regional studies, Sofia, Bulgaria
}

\begin{abstract}
The process of restructuring European economies has begun over the last decade. This process is related to the implementation of strategies and policies at all levels in the countries for sustainable development in context of climate change and reduction of natural resources usage. Logically, European course to decarbonizing economies was adopted two years ago. In this regard, it is important to monitor the transition of the economies of individual countries and regions to neutrality and what problems arise. In this sense, Bulgaria is part of this process, and it is important to develop policies, aiming to reformulate regional policy and achieving sustainable development of the Bulgarian regions. The aim of the present research is to analyze the state of the economy in Gabrovo district in the context of the concept of sustainable development and outlining the difficulties and opportunities of the local economy in the transition to neutrality. The author achieves the goal, using various approaches and research methods - systematic, territorial approaches and descriptive, comparative, statistical and other methods.
\end{abstract}

\section{Introduction}

In recent decades, interstate competition, technological progress, economic development, increased urbanization and increasing environment, reduction of green areas has led to significant climate change. The climate change has begun to affect a natural ecosystems and people's quality of life. The signed Green Deal between the EU Member States marks the beginning of a new stage in the technological development of the European economy. The deal outlines the new European economy, which imposes a new way of thinking. This act of European leaders shows that European countries are about to undergo profound transformations to create European economy that protects the environment. According to analyses by the International Energy Agency, in the coming years the countries of the European Union should triple the capacity for production of electricity from renewable sources, such as wind farms, and 25 times the production of electric vehicles. These and other decisions according to the Green Deal must lead to the transition of the European economy. The green deal has its specific dimensions in each European country and is also financially secure. The sustainable development as a concept is not new, but it has now been adopted by the EU. All countries need to formulate and prepare medium- and longterm goals and plans for restructuring their economies. This means that Bulgaria must use

\footnotetext{
*Corresponding author: n.tzonkov@unwe.bg
} 
European funding to readjust the national economy. This process involves closing traditional industries and investing in creating green jobs and industries of the future. The transition of the Bulgarian economy to green and blue is associated with a rethinking of national policies and a conceptual change in regional development, which is based on sustainable development of the regions.

\section{Results}

Based on the analyses that will be made about the state of the regional economy of Gabrovo district and the green jobs that are opened, the author will outline the opportunities and problems for the development of a green economy in the region. The region is characterized by the development of the secondary sector of the economy. But in recent years there has been a rise in the service sector. For example, the segment related to the production of software and information technologies are becoming an important branch of the regional economy. The aim of the study is to clarify the problems and factors influencing the development of the green economy of region. The methodology of the present study includes a set of different approaches and methods that are subordinated to the main goal. These methods include a systematic and territorial approach, as well as analytical, descriptive, statistical, comparative methods and reference to expert opinion.

\section{Discussion}

\subsection{Theory frame of the research}

The concept of sustainable development of the regions was first announced in the 1970s. In fact, modern ideas for the development of a blue and green economy are inextricably linked to the Brundtland plan, which sets out the strategies for the sustainable development of countries and regions. On the other hand, the sustainable development is enshrined in a number of strategic documents of the European Union, the United Nations, the World Bank, International Monetary Fund, the Kyoto and Paris Agreement which are aimed at combating climate change.

The green economy is defined as low-carbon, resource-efficient and socially inclusive. In a green economy, employment and wages' growth are driven by public and private investment in such economic activities, infrastructure and assets that allow reducing carbon emissions and pollution, increased energy and resource efficiency, and prevention of biodiversity loss and ecosystem services.[1] The green and blue economy is characterized by the development that is based on renewable and alternative energy sources. The green economy is not limited in establishing and maintaining environmental standards, but also control over the use of natural resources and building a social and economic ecosystem in the individual regions, which is based on the circular economy. An important component of the green economy is the social development of the regions and the improvement of the quality and living conditions. In practice, the transformation of the economic system into a green economy is associated with a rethinking of the economic interaction between the natural environment and people, and the process of replacing some raw materials with others. The transition to a green economy has been accompanied by the closure of some industries and the emergence of others. Therefore, the transition to a green economy changes the sectoral and territorial structure of the economy, the role and importance of individual regions in the national economy. 


\subsection{Characteristics of Gabrovo district in the context of the concept of green economy}

According to its main economic indicators, district ranks after the first ten districts in Bulgaria. The gross domestic product generated by the economy per capita in the amount of BGN 14,444 [2] in 2019 ranks district in fourth place among all 28 administrative districts. The main contribution to the local economy is made by the Manufacturing sector, which provides over half of the net sales revenues in the district. The most significant share in it has the enterprises operating at largest municipalities in the district. One of the leading economic activities in the industry are traditional for the region: machine building production of tools, lifting machines, instrument making; sanitary fittings; textile, clothing, and knitwear industry. The representatives of these industries are energy intensive and require the incorporation of environmentally friendly technologies. District is not an intensive agricultural region. This is due to the geographical position of the district, which includes mainly mountainous and foothill areas with predominant small and fragmented agricultural areas. A little over 1 million of agricultural land are managed on the territory of the district, of which about $67 \%$ is arable [3]. Therefore, studying the opportunities for development of a green economy in the district and considering the geographical features, we conclude that tourism is considered an important alternative sector for the socioeconomic development of municipalities in the district. The proximity of the region to the Balkan Mountains, the mountain air, the natural and historical-ethnographic landmarks, the architectural reserves and complexes, the cultural monuments make the area an attractive place for domestic and international tourism.

\subsection{Development of green economy and green jobs in Gabrovo district}

The population of Gabrovo district is 107,000 people in 2019. For 2019 the students, studying at the Technical University - Gabrovo, are 3 669. In the same year, the attracted foreign direct investments in the district are BGN 662 million. The venue of production in Gabrovo district is BGN 2.5 billion, and in the municipality of Gabrovo BGN 1 billion in 2018. For the period 2016 - 2018 the most dynamically developing sector is information technologies and services with a growth of 2.6 times [4].

Gabrovo municipality is the largest in the district. Therefore, it is logical to consider mainly the development of the regional city of the four in the district, because it gives the greatest economic contribution to the regional product.

Analyzing the demographic picture in Gabrovo, we notice the steady decline in population over the past ten years. At the beginning of the period since 2005 the population was 70,537 people and over the years it has been decreasing. In 2019 Gabrovo population reached 57,000 people.

In the economic sphere, the city of Gabrovo stands out with the relative stability according to some important indicators. First, we must pay attention to the growth rate of regional GDP of Gabrovo district, which changed from BGN 756 million in 2005 and gradually increased to BGN 1,150 million in 2014. The information on the municipality's website shows that this is primarily related to the inflow of investments into several manufacturing enterprises producing export-oriented goods (Figure 1). 


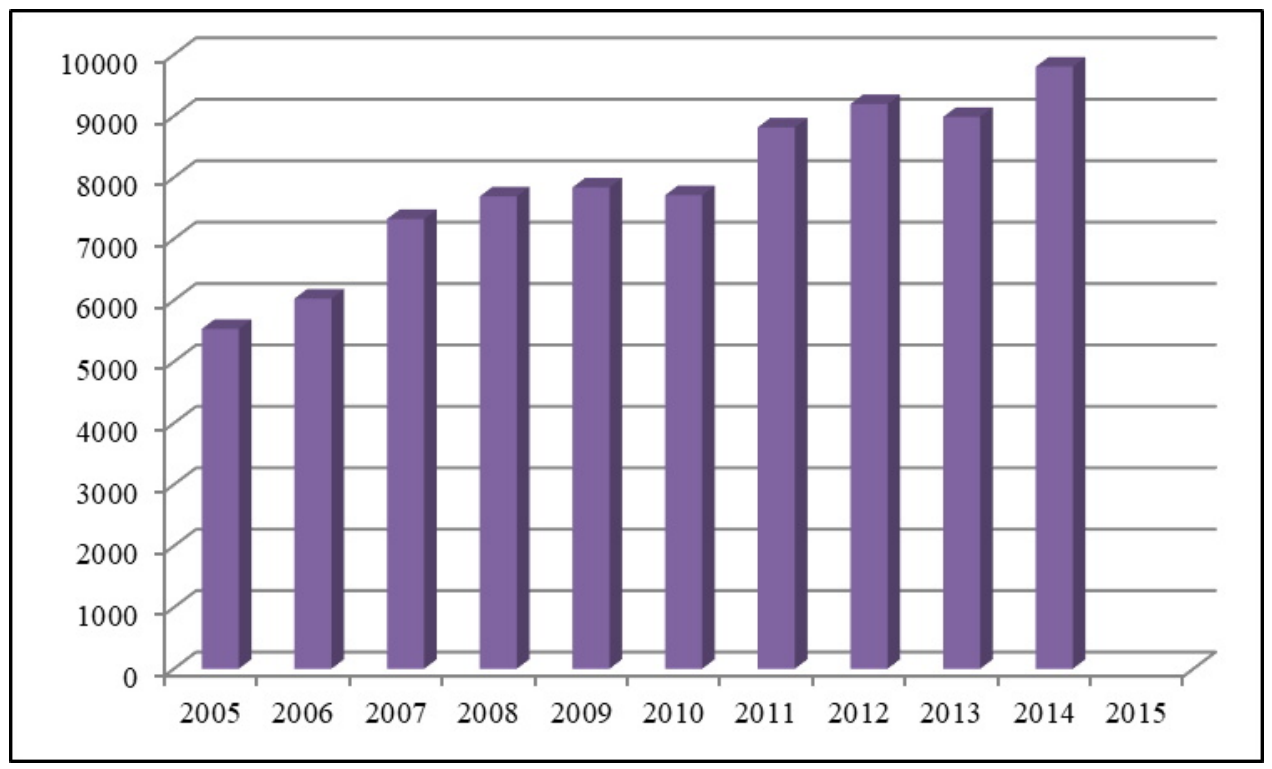

Fig. 1 GDP per capita at the municipality of Gabrovo (2005-2015). NSI source.

The analysis of the peculiar "breakdown" of GDP per capita also shows us an upward trend over time. In 2005, Gabrovo registered a value of BGN 5,534 per capita, and for the 10-years period it increases almost twice to BGN 9,804 per capita (2014). It is interesting in this case that the GDP growth is not related to the number of business units operating in the municipality.

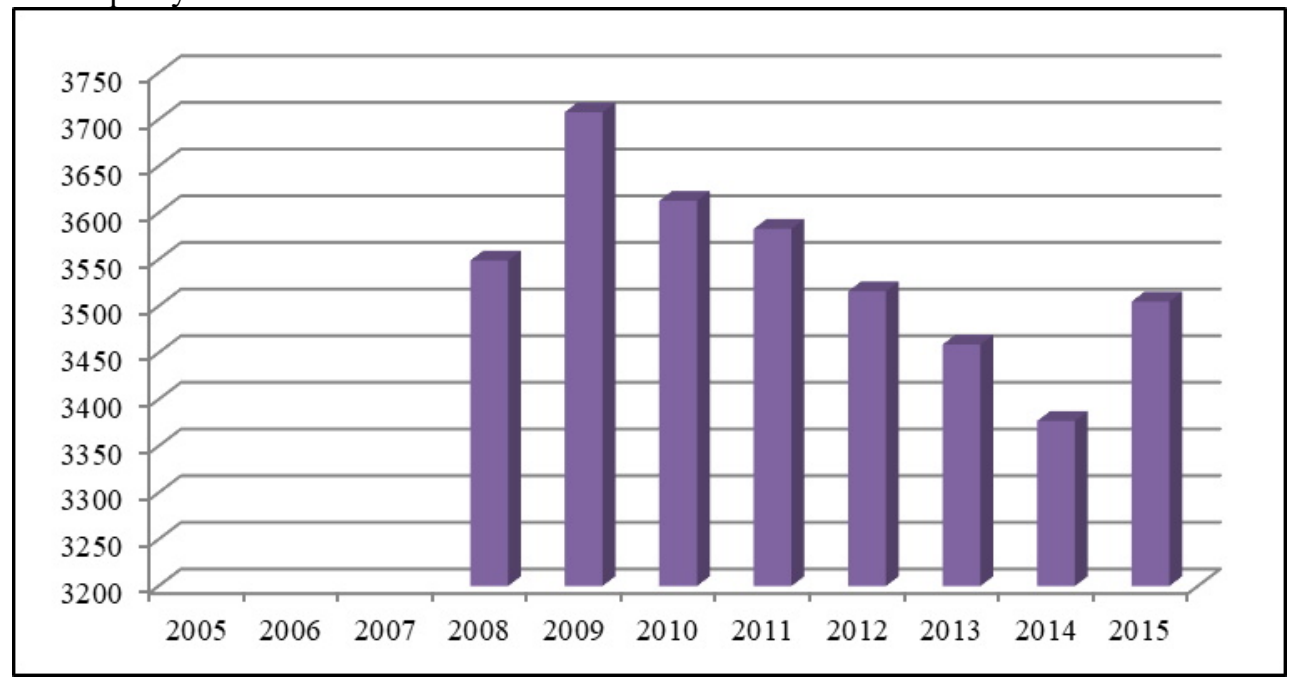

Fig. 2 Companies in Gabrovo district. NSI source. 


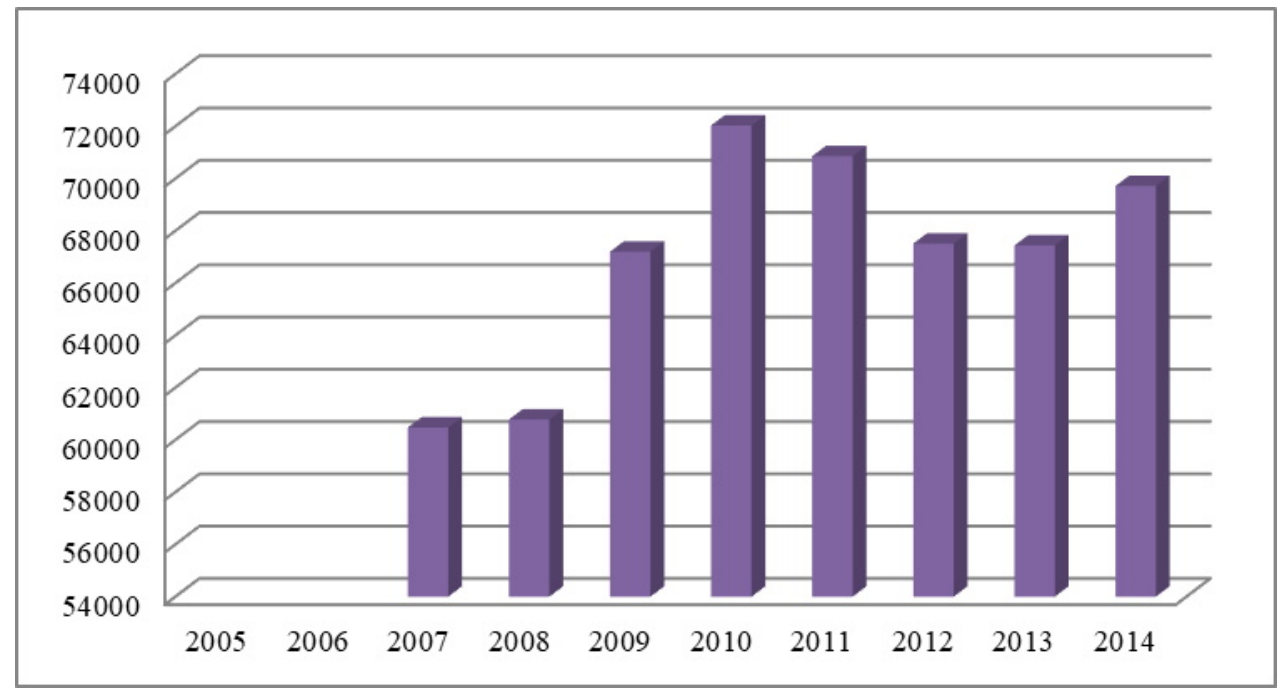

Fig. 3 FDI invested in the municipality of Gabrovo (2007-2014). Source: the official website of the municipality.

Investment activity in Gabrovo also marks interesting trends. Like the other monitored cities, a certain smoothness in the withdrawal and reduction of investments is reported, which continues to catch up in 2014, when the total volume was 69717.3 million of euros. But of interest is the fact that the peak investment moments are in 2010 and 2011, which corresponds to the decline in the levels of production in Gabrovo.

From the comparative characteristics derived so far it can be said that for the municipality of Gabrovo industry is a leading economic sector. Favorable factors for development are the industrial traditions, infrastructure and technical base, the presence of the Technical University in the town of Gabrovo and a skilled workforce. After expiration of the programming period 2007-2013 in 2015, a key factor for the municipal financial policy implementation is the optimal absorption of European Union funds, which finance programs by sectors with direct and indirect effects on growth, employment, wages, and competitiveness.

In recent years, district has made significant investments in improving a water infrastructure and living conditions in the four municipalities. In the annual ranking, which is made between the district cities in Bulgaria, is among the first in terms of quality of life in the last 10 years. The study for 2019 involves 27 major cities, which are evaluated on five main criteria economy, ecology, quality of life, education, security. Municipality is at first place for "best city to live"; and in the ranking of "the greenest city". The reasons for this obstacle are different. On the one hand, the structure of the regional economy has undergone significant changes in recent decades. Many heavy and light industries have closed or reduced their workload. Second, the government is working purposefully to improve the living conditions, which is associated with the replacement of water supply and sewerage, more green spaces, separate waste collection and other steps in this direction. Third, municipalities and enterprises have been gasified, which leads to a reduction in harmful emissions into the atmosphere. The private investments are also invested, which means that companies can meet the required ecological standards. The state is also acting purposefully, adopted a new program, related to the labor market. The purpose of this measure is stimulation of the green jobs establishment. In recent years, the municipalities in the district have been working hard to change the local economy and turn it into greens. According to Albena Miteva "Green jobs" are jobs that contribute to increasing 
environmental resilience, including reducing carbon emissions, protecting biodiversity and ecosystems, and adapting to climate change" [5]. Therefore, all investments made using European funding in infrastructure and stimulation of small and medium enterprises support the district transition to a green economy. The municipality of Gabrovo, for example, is one of the municipalities with the largest volume of attracted European funds. At the same time, there are few problems arising from the restructuring of the local economy. According to the research of the Institute of Market Economy (IME) [5], district is at seventh place for the last year in the number of generated waste per capita. This circumstance comes to say that targeted action is needed to improve the waste collection and treatment system. There is also no landfill for construction waste. It is also noteworthy that the district maintains a high level of unregulated landfills. On the other hand, the territory of the district is part of 2000 , which naturally means that high ecological standards of local ecosystems must be maintained.

Turning the local economy green means changing the energy sources, the way, and the culture of the population's thinking. The regional economy is energy-intensive, with coal and wood still being used for heating. And they are a big polluter. Another major pollutant is vehicles. To address these challenges, it is important to expand the gas deliveries to industrial and domestic consumers. Public transport must switch to environmentally friendly vehicles. This process has stalled, with public transport using methane. In terms of way of thinking and culture, it is necessary to rethink the views of the population. It is crucial to introduce energy savings, rational and reasonable consumption of water and other resources as a basic principle. The final stage of this process is incorporation of the circular economy. Industrial and household waste should be recycled and reused. Other important activities that need to be started are related to the introduction of new technologies in the individual industries. For example, strengthening energy efficiency, which can be achieved by facilitating buildings to alternative energy sources, greenery on the facades and other modern alternative decisions.

\subsection{Comparative analysis of the integrated plans for development of the municipalities (2014-2020) in the context of green economy development in Gabrovo District}

In the annual analysis for the regional profiles of IME the state of the environment and ecology of district is assessed as very good. In 2018, the data shows a decrease in the amount of household waste collected per capita. Thus, district ranks first in ecological status. Carbon dioxide emissions are more than ten times lower than their relative volume in the country. Relatively high share of the population has access to sewerage $85.1 \%$ of the inhabitants of the district are in settlements with public sewerage (compared to $76.2 \%$ in the country), and $74.5 \%$ are connected to a wastewater treatment plant (compared to $63.9 \%$ in the country). The volume of generated municipal waste in the district is relatively high (433 $\mathrm{kg}$ / person per year compared to $409 \mathrm{~kg}$ / person in the country), but the share of waste provided for treatment and recycling reaches $91 \%$ (compared to $71 \%$ in the country) [6]. All four municipalities in the district have developed plans for environmental protection. The comparative analysis of the municipal development plans of the municipalities of district for the period 2014-2020 shows that the share of employees and the number of companies of the tertiary sector is large. This fact illustrates that most economic activities are environmentally friendly. Including more serious attention is paid to the tourism industry in the district and municipalities. This is one of the brightest representatives of the green economy in the district. In recent years, a large amount of European funds has been invested in improving environmental infrastructure and energy efficiency. An important component of the green economy is the system of garbage collection, disposal, and 
processing, which represents a significant share of expenditures in municipal budgets. What remains to be done is to continue improving the system by completing the cycle of the circular economy in the district.

Table 1. PEST analysis of Gabrovo District

\begin{tabular}{|c|c|}
\hline Criteria & Gabrovo District \\
\hline Political factors & Stable environment \\
\hline Economic factors & $\begin{array}{c}\text { Friendly regulatory, business, industrial and tax } \\
\text { environment }\end{array}$ \\
\hline Social factors & $\begin{array}{c}\text { Negative demographic processes and not balanced } \\
\text { demographic structure and labor market }\end{array}$ \\
\hline Technological factors & $\begin{array}{c}\text { Industry traditions, educational infrastructure, good } \\
\text { connection between education and business }\end{array}$ \\
\hline
\end{tabular}

Political factors. The political environment in the municipalities of Gabrovo district is a function of the national policy. The area is characterized by relative stability and investment potential due to the formed business environment.

Economic factors. The complex of a system of local taxes and fees, the business climate, the regulatory framework, the developed industry, and traditions, settle favorable conditions. Therefore, economic factors improve the business environment.

Social factors. Social factors strongly influence the economic development of the district. Among the social factors with the most negative impact is the deteriorating demographic structure of the population and the labor market. On the other hand, there is a developed educational infrastructure - vocational schools and a Technical university in Gabrovo Municipality.

Technological factors. In Gabrovo region there are objective prerequisites for the formation of economy 4.0 and development of green technologies due to the accumulated industrial traditions, educational infrastructure, which involves technological renewal and development, the technology park in Gabrovo, and the ability to combine scientific capacity with business in the area.

\section{Conclusions}

Attempts to analyze the transition of district to a green economy and its results lead to some conclusions. They are related to the policy of municipalities, the state, citizens, and companies regarding environmental protection, change of habits, thinking, culture, incorporation of innovative practices and technologies in the field of ecology, improvement of the system for waste collection and treatment, as well as continuing the process of improving energy efficiency. The combination of all these areas will lead to the introduction of a circular and green economy in the region.

A big direction in connection with the transformation of the local economy into green is the replacement of vehicles with environmentally friendly ones, which is associated with serious private investments of citizens, which they do not have. That is why a purposeful policy of subsidizing the state and municipalities in this direction must be considered. The second major area of work is to continue the industrial and domestic, which will also lead to the of the economy of district.

The local economy of district has begun its transformation, but it has a long way to go before it becomes a green economy. The regional economy has the potential to be consistently developed with specific investment and innovation policies, building on the existing industrial, economic, educational, and technical infrastructure. According to the Regional Bonus System of the North Central Region, the thematic area "Mechatronics, 
innovation and Clean Technologies"; is indicated with the greatest potential for development. The capacity for intelligent specialization of district is concentrated in thematic areas "Informatics and ICT"; and "Mechatronics and clean technologies". Positive factors include the traditions, the built material and technical base, the presence of vocational technical high schools and the Technical University. Technical university in Gabrovo envisages the creation of an innovative center of competence "Eco- and energysaving technologies" with areas: electric vehicles, laser technology, systems for recognition of materials and environments, power electronics, design in mechanical engineering, systems, energy efficient lighting systems [7].

\section{References}

1. UN environment program, Green Economy, Online, https://www.unep.org/regions/asia-and-pacific/regional-initiatives/supporting-resourceefficiency/green-economy

2. National Statistical Institute, Bulgaria, https://www.nsi.bg/en

3. Gabrovo District Administration, http://www.gb.government.bg/index.php/2014-1104-15-02-27/ikonomika

4. InnovaGab, Business platform, Municipality of Gabrovo (2019) Invest in Gabrovo: Green, smart \& innovative, https://www.discover.gabrovo.bg/2020-bg/

5. A Miteva, Altern. J., 1 (2017)

6. Institute of Market Economy, Regional Profiles 2020, https://www.regionalprofiles.bg/bg/

7. Gabrovo District Administration, Report: Study of the innovation potential of the municipality of Gabrovo in the field of industry (2017) 